\title{
A FORMAÇÃO DE PROFESSORES NO BRASIL: HISTÓRICO E DESDOBRAMENTOS
}

\section{TEACHERS' TRAINING IN BRAZIL: HISTORY AND ITS RESULTS}

\author{
Luciana Paula Vieira Castro ${ }^{1}$ \\ Vilmar Malacarne ${ }^{2}$ \\ Dulce Maria Strieder ${ }^{3}$
}

\begin{abstract}
Resumo: A formação de professores tem registros em todo o Planeta desde seu início em meados do século XI, a fim de amparar as práticas dos profissionais que atuavam em instituições de ensino à época. Tendo em vista a importância da história da educação para compreensão da realidade educacional atual, neste texto, via pesquisa bibliográfica, serão apontados aspectos da formação de professores a partir da análise do contexto histórico e atual no campo educacional e social. Atualmente, em termos legais, a prioridade empleitear a docência no Brasil, na Educação Básica, nos níveis Fundamental e Médio, é para profissionais graduados em cursos de Pedagogia e Licenciaturas. Em um panorama de constantes mudanças no campo educacional, atualmente, ser professor distingue-se de períodos anteriores, distinção essa, muitas vezes, não assistida no contexto da formação docente. Apesar de terem ocorrido alterações na formação dos professores no país, ainda há a necessidade de repensar sua estrutura, de maiores investimentos governamentais e reconhecimento social para que a formação e a atuação docente sejam mais efetivas.
\end{abstract}

Palavras-chave: História da educação; Formação de professores; Políticas de formação de professores.

\begin{abstract}
The teachers training has been recorded throughout the Planet from its beginning in the middle of the eleventh centuryto support the professionals' practices in educational institutions at the time. It should be highlighted the importance of the history of education to perceive the current educational reality, in this text, based on bibliographic research. So, some aspects of teachers' training will be pointed out to analyze the historical and current context in educational and social field. Currently, according to the legal terms, the priority to apply for teaching in Brazil, in Basic Education, at elementary and Middle school levels, is for professionals who are graduated in Pedagogy and Undergraduate courses. According to a scenario of constant changes in educational field, today, there is a distinction to be a teacher nowadays when compared to the previous periods. Such distinction has not been often assisted in the teacher's trainingcontext. Although there have been changes in teacher's training in Brazil, there is still a need to rethink its structure, as well as greater government investments and social recognition so that training and teaching activities can be more effective.
\end{abstract}

Keywords: History of education; Teacher's training; Teacher's training policies.

\footnotetext{
${ }^{1}$ Doutora em Ensino de Ciências e Educação Matemática (UEL). Professora temporária da Secretaria do Estado da Educação do Paraná, SEED/PR, Cascavel, Paraná, Brasil. E-mail: professoralucianacastro@ hotmail.com

${ }^{2}$ Doutor em Educação pela Universidade de São Paulo (USP). Docente do Programa de Pós-Graduação em Educação em Ciências e Educação Matemática (PPGECEM) da Universidade Estadual do Oeste do Paraná (Unuioste), Cascavel, Paraná, Brasil. E-mail: vilmar.malacarne@unioeste.br

${ }^{3}$ Doutora em Educação pela Universidade de São Paulo (USP). Docente do Programa de Pós-Graduação em Educação em Ciências e Educação Matemática (PPGECEM) da Universidade Estadual do Oeste do Paraná (Unuioste), Cascavel, Paraná, Brasil. E-mail: dulce.strieder@unioeste.br
} 


\section{Panorama histórico da formação de professores}

A formação de professores no mundo é realizada há muito tempo. Provavelmente, de acordo com Saviani (2009), teve início em meados do século XI, pois havia já nesta época, instituições de ensino, e os professores que lá atuavam certamente recebiam alguma formação para lecionarem.

Os registros de escolas específicas para formação de professores no Brasil datam de um período muito posterior a este, como percebemos em Cavalcante (1994), que afirma que as escolas para formação do professor para ensino primário ${ }^{4}$, no Brasil, existem desde o século XIX.

Neste período, diante da inevitável universalização da instrução elementar no país, houve também a alta demanda pela formação de professores para lecionar nas escolas e "o caminho encontrado para equacionar essa questão foi a criação de Escolas Normais, de Nível Médio, para formar professores primários, atribuindo-se ao nível superior a tarefa de formar os professores secundários” (SAVIANI, 2009, p. 148).

Conforme Peres (2010) e Saviani (2009), a preocupação com a questão da formação de professores foi registrada na Lei das escolas de Primeiras Letras, no ano de 1827. Essa Lei determinava que os professores fossem formados com seus próprios investimentos nas capitais de cada província, com ênfase no preparo didático ${ }^{5}$, mesmo que ainda não houvesse menção ao preparo pedagógico ${ }^{6}$ (SAVIANI, 2009).

Ainda de acordo com tal Lei era preciso oferecer em todos os locais mais populosos as escolas de primeiras letras, com professores vitalícios, admitidos por concurso público, formados com uso do método lancasteriano ${ }^{7}$, com treinamento de dez alunos mais adiantados para atuar no ensino dos demais durante metade do tempo das aulas e estudarem junto aos professores na outra metade das aulas (PERES, 2010).

O Ato Adicional de 1834 pôs a instrução primária na competência das províncias e, por conta disso, a formação de professores seguiu sob a alçada também das províncias, as quais adotaram o modelo europeu de formação de professores as escolas

\footnotetext{
${ }^{4}$ Nível de ensino equivalente ao que atualmente conhecemos por séries iniciais do ensino fundamental.

5 Ensinamentos voltados para a compreensão da forma de ensinar, com os pressupostos teóricos que norteiam a atividade docente a fim de torná-la mais eficaz (HOUAISS; SALLES, 2001).

6 Ensinamentos voltados para aspectos da pedagogia e do desenvolvimento do aluno (HOUAISS; SALLES).

${ }^{7}$ Também conhecido de ensino monitorial ou mútuo, esse método foi desenvolvido na Inglaterra por Bell e Lancaster em 1835 (MALACARNE, 2007; SAVIANI, 2009).
} 
Normais, sendo implantada a primeira na então província do Rio de Janeiro, em Niteróiem 1835 (MALACARNE, 2007; SAVIANI, 2009) ${ }^{8}$.

Em seguida, o mesmo modelo foi implantado em várias outras províncias: na Bahia, Mato Grosso, São Paulo, Piauí, Rio Grande do Sul, Paraná, Sergipe, Espírito Santo, Rio Grande do Norte, Paraíba, Santa Catarina, Goiás e Maranhão, funcionando de modo intermitente, sendo constantemente abertas e fechadas (CAVALCANTE, 1994; SAVIANI, 2009).

Além de Minas Gerais, Amazonas, Pernambuco, Alagoas e Pará (CAVALCANTE, 1994), e ainda, Rio de Janeiro (antigo Distrito Federal - DF) e Ceará (SAVIANI, 2009). Nestas escolas não predominava a preparação dos professores com ênfase nos conhecimentos didático-pedagógicos, mas nos conhecimentos relativos aos saberes a serem transmitidos para as crianças (SAVIANI, 2009).

Ainda que a falta de professores com formação adequada contribuísse, até em meados de 1835, dificultando a expansão e melhora do ensino elementar (PERES, 2010), as escolas Normais foram consolidadas apenas em 1870, em decorrência da obrigatoriedade da escolarização primária (MALACARNE, 2007). Tais escolas tinham a princípio, como público-alvo, somente os homens (CAVALCANTE, 1994; MALACARNE, 2007).

O recrutamento de mulheres para a docência só ocorreu no fim do século XIX, bem como sua escolarização em nível médio (GATTI, 2010). Até 1914 a oferta do ensino médio vocacional, e neste, as escolas Normais para as mulheres de classe média, permitia que as mulheres interessadas em trabalhar com a docência se preparassem para isso (TEIXEIRA, 1968). Mas a consolidação das escolas de formação de professoras tardou muito em acontecer.

Peres (2010) especifica o ano de 1878 como o ano do início de oferta exitosa das instituições de ensino femininas, inclusive com instituições de altíssima qualidade, sendo que uma delas ofertava formação completa incluindo até pedagogia para as mulheres interessadas.

A formação do professor normalista foi, durante o século XIX, uma formação que recebeu críticas e, entre elas, a de Couto Ferraz (SAVIANI, 2009). Em 1854, época de Couto Ferraz, as poucas Escolas Normais estavam em péssimo estado de

\footnotetext{
${ }^{8}$ Em face da falta de consenso encontrada na literatura sobre a cronologia da instalação das Escolas Normais nas diversas localidades, optamos por mencionar apenas as localidades sem detalhamentos sobre a datação deste fato.
} 
conservação, com poucos professores capacitados para a manutenção deste tipo de instituição e com baixa qualidade da formação provincial oferecida (PERES, 2010).

Assim, Couto Ferraz as classificava como dispendiosas e ínfimas em termos numéricos de profissionais formados e, por conta disso, o presidente da Província do Rio de Janeiro fechou a Escola Normal de Niterói, em 1849, colocando em lugar da atuação dos professores formados nesta, a dos professores adjuntos, que atuariam como auxiliares dos professores regentes, aprimorando as disciplinas e práticas de ensino (SAVIANI, 2009).

Esse meio de formação de professores não progrediu e continuaram a ser instalados os cursos normais e a primeira escola normal, a de Niterói, foi reaberta (Idem). Houve, entretanto, em meados de 1879, uma controvérsia. Com a implantação do Decreto de 1879, sob alçada do Ministro Carlos Leôncio de Carvalho, foi permitido que "qualquer cidadão, nacional ou estrangeiro, pudesse lecionar o que quisesse, sem passar por provas de capacidade” (PERES, 2010, p. 15).

Não fazia sentido, pensando na formação de professores que vinha sendo oferecida há várias décadas nas Escolas Normais e estava se consolidando desde 1870, que se permitisse a qualquer pessoa, sem testes de aptidão, exercer a docência, mas ainda assim foi o que o decreto passou a permitir, devido à quantidade de professores demandados.

Em 1880 foi criada a Escola Normal, gerida pelo Poder Público (Op. Cit.), mas podemos afirmar que a dinâmica de funcionamento das Escolas Normais foi firmada a partir da reforma da instrução pública no estado de São Paulo, em 1890, que foi caracterizada pelo enriquecimento dos conteúdos e primazia pelo treinamento das práticas de ensino (SAVIANI, 2009). Tal reforma se repetiu nas principais cidades do Estado de São Paulo, tornado-se modelo de formação, de modo que professores de outros estados mandavam professores para estas escolas para aprender ou recebiam professores destas escolas para ensinar, permitindo a expansão do padrão da Escola Normal para os demais estados (Ibidem).

No começo dos anos 1900 ocorreram as primeiras explicitações de preocupação com a formação dos professores para atuarem no que equivale hoje ao então ensino secundário (UNESCO, 2009; GATTI, 2010).

Mesmo com a consolidação das Escolas Normais, o padrão em expansão não contribuiu muito, trazendo ainda ranços do padrão dominante até então, com ênfase nos conhecimentos a ser trabalhados (SAVIANI, 2009). 
Ainda assim, na década de 1920, em decorrência da ampliação da escolarização primária, houve a criação das escolas Normais regionais, com curso de formação limitado ao primeiro ciclo do curso secundário, período no qual a formação dos professores, assim como a jornada escolar, ocorreu em período reduzido, com improviso e inadequação na formação (TEIXEIRA, 1968).

Em 1930, partindo da formação de bacharéis, foi adicionado mais um ano de curso para a formação em licenciatura, num modelo que ficou conhecido por " $3+1$ " (UNESCO, 2009; GATTI, 2010). Esse modelo de formação, conforme Saviani (2009), é agregado às décadas de 1940 e 1950.

Independentemente de divergências na cronologia da implantação do modelo “ $3+1$ ”, importa dizer que neste modelo havia a formação do profissional nas áreas específicas de cada conteúdo e em um ano adicional do curso havia aprendizagem dos conteúdos da área de educação (UNESCO, 2009; GATTI, 2010).

Em 1931, com a Reforma Francisco Campos, foi instituída a formação de professores para o ensino secundário em nível superior, que formou seis anos depois os primeiros educadores para este nível de ensino (MALACARNE, 2007).

Em 1932, foram implantados os institutos de educação, tendo como pioneiros, o Instituto de Educação do Distrito Federal, idealizado e implantado por Anísio Teixeira e o Instituto de Educação de São Paulo, em 1933, Fernando de Azevedo, visando atingir os ideais da pedagogia, que objetivava se consolidar como um conhecimento de caráter científico (SAVIANI, 2009).

O ofício de ensinar foi considerado uma profissão com formação superior por meio do decreto $\mathrm{n}^{\circ}$ 19.581/37, que outorgou o Estatuto das Universidades Brasileiras e oficializou a criação de três áreas de formação em licenciatura: de Educação, de Ciências (Matemática, Química e Ciências Naturais) e de Letras (MALACARNE, 2007). Nesse contexto, os Institutos de Educação foram brevemente transformados, como afirma Saviani (2009, p. 146):

[...] os Institutos de Educação do Distrito Federal e de São Paulo foram elevados ao nível universitário, tornando-se base dos estudos superiores de educação: o paulista foi incorporado à Universidade de São Paulo, fundada em 1934, e o carioca foi incorporado à Universidade do Distrito Federal, criada em 1935.

Os cursos de formação de professores em nível superior foram difundidos para todos os Estados do país após a promulgação do decreto-lei ${ }^{\circ} 1.190 / 39$, que organizou a Faculdade Nacional de Filosofia da Universidade do Brasil, e serviu de referência para 
as outras escolas de nível superior (SAVIANI, 2009). Do mesmo decreto-lei $\mathrm{n}^{\circ}$ 1.190/39 resultou o modelo de formação em cursos de Pedagogia e Licenciatura (Idem).

O curso de Pedagogia foi regulamentado em 1939 para preparar bacharéis especializados em educação e complementar formação de professores para as Escolas Normais, com habilitação também para lecionar disciplinas no Ensino Secundário (UNESCO, 2009; GATTI, 2010).

A implantação do curso se deu no momento de intensas discussões sobre a implantação das Universidades no país, estimulados pelas reflexões da Associação Brasileira de Educação (ABE) e por ideias da Escola Nova, que objetivavam transformações sociais por meio da Educação (PAPI, 2005).

Assim, diante da falta de um conteúdo específico para o curso de pedagogia, houve o desenvolvimento de um currículo que abrangia aspectos gerais de outras ciências como psicologia, sociologia e filosofia, formando o bacharel em pedagogia como técnico em educação e fazia, em seguida, o curso de didática, capacitando-se como licenciado em pedagogia (PAPI, 2005).

Já os cursos de licenciatura capacitavam professores para lecionar várias disciplinas nas escolas secundárias, enquanto que os cursos de Pedagogia para lecionar nas escolas Normais Superiores (SAVIANI, 2009). Tanto o curso de Pedagogia quanto os demais de licenciatura eram oferecidos no modelo "3+1" (SAVIANI, 2009; UNESCO, 2009; GATTI, 2010).

Conforme afirma documento da UNESCO (2009) e Gatti (2010), a distinção entre o professor polivalente para as séries iniciais e o professor especialista, para as séries subsequentes ficou desta forma marcada, e permanece até os dias atuais, tanto em relação à formação, à carreira e, sobretudo, no reconhecimento da sociedade, mesmo após a exigência da formação dos professores com formação superior. Esta representação associada aos interesses que envolvem a formação de professores dificulta elaborações e transformações nas bases estruturais das instituições e cursos de formação (GATTI, 2010).

Cavalcante (1994), afirma que em torno do ano de 1946 houve intensas mobilizações em favor da:

[...] criação de faculdades de educação, ciências e letras para formação do professor primário, estenderiam sua influencia até na preparação do professor primário, uma vez que também formariam professores para aquele nível de escolarização. Desde então começaram as críticas aos novos professores, baseados no argumento de que eles não apresentavam a experiência e os conhecimentos desejáveis a um professor primário (p.31). 
No mesmo ano foi editada a Lei Orgânica de Ensino Normal, que obrigou os estados a reorganizarem os cursos para atendimento da referida lei, que visava uniformizar e melhorar o ensino, por meio da consolidação de diretrizes e normas nacionais (CAVALCANTE, 1994). Mas na percepção de Tanuri (2000), essa lei não trouxe grandes avanços, tendo apenas consolidado um modelo de ensino normal que já estava presente em vários estados.

Tal como as outras modalidades do então ensino de segundo grau, o curso Normal foi separado em dois ciclos, que capacitava no primeiro professores regentes do ensino primário, em quatro anos de formação e funcionaria em Escolas Normais regionais, enquanto que o segundo ciclo, que durava três anos, correspondia ao colegial do curso secundário, capacitando professores do ensino primário em Escolas Normais e nos institutos de educação. Tais institutos teriam jardim de infância e escola primária anexos e ministrariam também cursos de especialização de professores primários para as áreas de Educação Especial, Ensino Supletivo, Desenho e Artes, música e canto e cursos de administradores escolares para formar diretores, orientadores e inspetores escolares (CAVALCANTE, 1994; TANURI, 2000; SAVIANI, 2009).

A complementação da formação nos aspectos didático-pedagógicos, ocorrida no último ano do modelo " $3+1$ " em nível superior era exercida pelos Departamentos de Pedagogia das Faculdades de Filosofia, Ciências e Letras, na década de 1960, e pelas Faculdades de Educação em meados de 1970 (SAVIANI, 2009).

Em nível médio, durante a década de 1960, a Escola Normal foi a mais requisitada para formação profissional (CAVALCANTE, 1994). Entretanto, após uma época de prestígio social, a atuação docente chegou a um desprestígio enquanto categoria e, ao mesmo tempo, começou a receber estudantes oriundos de classes mais desfavorecidas (MALACARNE, 2005).

A queda brusca na procura por essa formação, ao longo da década de 1970, esteve relacionada à descaracterização e decadência do valor social atribuído à docência (CAVALCANTE, 1994).

Essa situação de desprestígio culminou “com a Lei 5692/71, que define o critério de carência econômica, além do desempenho escolar, como requisito para o acesso aos cursos de formação de professores" (MALACARNE, 2005, p. 23).

Em termos do curso normal, com a implantação da Lei de Diretrizes e Bases (LDB) Lei n ${ }^{\circ}$ 4.024/61 não houve significativas mudanças em relação à Lei Orgânica de 1946, continuando o mesmo a ser ofertado na mesma dinâmica (CAVALCANTE, 
1994). Mas, em relação aos os currículos dos cursos superiores, Papi (2005, p. 75) afirma que

\begin{abstract}
Com a homologação da primeira lei geral da educação, Lei $\mathrm{n}^{\circ} 4.024 / 61$, foi previsto o estabelecimento de um currículo mínimo para os cursos superiores, o que ocorreu também para o Curso de Pedagogia, através do Parecer $\mathrm{n}^{\circ}$ 251/1962, regulamentado pelo antigo Conselho Federal de Educação (CFE). Com esse currículo foi reforçado o esquema anterior, que favorecia a ruptura entre os estudos teóricos e práticos.
\end{abstract}

Na verdade, a Lei Orgânica do Ensino Normal (1946) e a Lei $n^{\circ} 4.024 / 61$ tiveram caráter de segregação, ao opor o ensino popular e o de elite, pois destinava ao $1^{\circ}$ ciclo somente os financeiramente desfavorecidos, que se formavam como professor regente para atuar apenas na área rural, com função de formação final; ao passo que o $2^{\circ}$ ciclo, ainda que fosse mais especializado e diversificado, permitia a continuação dos estudos o exercício da função docente na área urbana (CAVALCANTE, 1994).

A reforma universitária implantada em 1968, já em um contexto de ditadura militar, por meio da Lei $n^{\circ} 5.540$, ocasionou mudanças nos cursos de formação de professores, separando a faculdade de Filosofia em setores ou departamentos, ao passo que a Educação ${ }^{9}$ foi elevada à posição de Faculdade (PAPI, 2005).

Em 1969, com o Parecer $n^{\circ}$ 252, foi extinta a diferenciação entre bacharelado e licenciatura, sendo implantada a licenciatura plena (PAPI, 2005), isso em nível superior. Em nível médio, a partir de 1971, por meio da Lei $\mathrm{n}^{\circ}$ 5.692, foram extintas as Escolas Normais, e a formação oferecida por elas passa a ser ofertada em uma habilitação do ensino secundário, conhecida por Magistério (UNESCO, 2009).

Mesmo com essa mudança, os currículos da maioria dos cursos de formação em Magistério em muito deixavam a desejar (CAVALCANTE, 1994). Além disso, o curso era ofertado em locais em situação de precariedade, mesmo os ofertados pelos Institutos de Educação, faltando laboratórios, acervo bibliográfico, material e professores habilitados para a formação de novos professores (CAVALCANTE, 1994).

Agravando ainda mais a situação, não existia controle para a criação destes cursos, que cresciam desordenadamente, uma consequência da obrigatoriedade da profissionalização de segundo grau, atendendo a Lei $n^{\circ} 5.692 / 71$, à alta demanda e aos baixos investimentos que demanda para sua implantação (CAVALCANTE, 1994).

A Lei $\mathrm{n}^{\circ} 5.692 / 71$ conjecturou a formação dos professores das séries finais do segundo grau em nível superior, nos cursos de licenciatura curta, com duração de três

\footnotetext{
${ }^{9}$ Estabelecimento de ensino.
} 
anos, ou plena, com quatro anos para conclusão (SAVIANI, 2009). Entretanto, a implantação das licenciaturas curtas para capacitar docentes para ensino de nível fundamental causou discussões e, por conta disso, o então CFE passou a orientar para progressivamente se alterarem essas licenciaturas curtas para licenciaturas plenas, para que estas fossem habilitações progressivas (UNESCO, 2009).

Assim, para aperfeiçoar os professores do ensino básico, o CFE aprovou a Indicação $n^{\circ}$ 08/86, que sugere a extinção da formação em licenciatura somente nas capitais, haja vista a facilidade da oferta de cursos superiores nas mesmas e a classificação de curso transitório conferido a esses cursos pela Lei (Idem).

Visando melhorias o Governo Federal criou em vários Estados os Centros Específicos de Formação e Aperfeiçoamento (CEFAM) para melhorar a formação dos professores das séries iniciais, superando problemas de formação na Habilitação do Magistério (UNESCO, 2009). Estes Centros foram implantados progressivamente a partir de 1983, pelo Ministério da Educação (MEC) em parceria com as secretarias de educação (CAVALCANTE, 1994).

Nesta fase, o curso de Pedagogia ficou incumbido da formação de professores para Habilitação Específica de Magistério (HEM) e especialistas em Educação, entendidos como gestores escolares, em cargos como diretores, orientadores, supervisores e inspetores de ensino (SAVIANI, 2009).

Houve distinção no enfoque a ser dado na formação dos professores, que resultou numa formação em licenciaturas que prima pelo aprofundamento em áreas disciplinares nos cursos de licenciatura, pondo em plano secundário a formação didático-pedagógica, como um apêndice concebido como mero formalismo para a habilitação para a docência. (Idem).

Nesse aspecto, o curso de Pedagogia, tal como o curso Normal, foi caracterizado por embates políticos, uma vez que, mesmo com seu objeto voltado para os parâmetros didático-pedagógicos, estes foram por vezes entendidos como conteúdos a serem aprendidos (Idem).

Compreendemos que, tal como afirma Saviani (2009), tem prevalecido nos cursos de formação de professores em Universidades e nas demais IES o modelo dos conteúdos culturais cognitivos, no qual a formação de professores para o ensino secundário trata a fundo somente a "cultura geral e o domínio da área de conhecimento correspondente à disciplina que irá lecionar”(p. 149). 
Nas Escolas Normais preparatórias para as séries iniciais, prevaleceu o modelo pedagógico didático, e de forma oposta a outros modelos, na qual há a ideia de que a formação do professor só será concluída com a efetividade da formação pedagógica.

Em 1986 o CFE aprovou a reformulação do curso de Pedagogia, facultando a esses cursos a oferta de formação também para a docência das quatro séries iniciais, como algumas instituições de ensino já faziam de modo experimental (UNESCO, 2009; GATTI, 2010). Entretanto, a habilitação oferecida pelo curso Normal também poderia se dar na formação em Pedagogia/habilitação magistério, e este foi fator que influenciou para a confusão na definição da função deste nível (CAVALCANTE, 1994).

Com a aprovação da Constituição Federal (CF) de 1988, ficou instituído que o professor teria planos de carreira (UNESCO, 2009), mas isso não foi suficiente para a elevação do status da profissão. Além disso, na CF foi prevista ainda a universalização da escolarização básica a todos e isso, além dos problemas nos cursos de formação, afetou profundamente a formação dos professores, como afirma Cavalcante (1994):

[...] crescimento da escola básica, que trouxe muitas alterações ao trabalho do professor, dentre as quais destacamos a necessidade de buscar alternativas didático-pedagógicas para atender crianças de classes populares; a segunda diz respeito à descaracterização dos cursos de formação. Enquanto uma escola se ampliava, a outra se deteriorava (p. 19).

Desta forma, além das questões políticas que afetaram os cursos de formação, houve a questão do despreparo dos professores para lidar com as condições materiais tanto dos alunos, quanto das escolas, que para o contexto, se fazia nova, uma vez que outrora atendia poucos alunos e nesse outro contexto, passou a atender muitos alunos. Em 1996 foi aprovada a nova LDB, por meio da Lei 9.394 (BRASIL, 1996).

Mas em relação à formação de professores, na percepção de Malacarne (2007), UNESCO (2009) e Gatti (2010), ao se alterarem nesta lei as sugestões nos currículos para as instituições de ensino e cursos, foi estabelecido o período de dez anos para implantação efetiva da mesma, admitindo oferta temporária dos cursos Normais em nível médio.

Assim, possibilitou-se uma prática que já não era mais cabível para o contexto (MALACARNE, 2007), e que deixou ranços da legislação anterior na base curricular dos cursos de formação de professores (UNESCO, 2009; GATTI, 2010). Mas UNESCO (2009) pondera sobre este prazo, afirmando que este período foi importante porque:

[...] nessa época, a maioria dos professores do ensino fundamental (primeiros anos) possuía formação no magistério, em nível médio, havendo também milhares de professores leigos, sem formação no ensino médio como até então era exigido. Seriam necessários tempo, muito esforço e financiamentos 
para chegar a formar esses docentes em nível superior (UNESCO, 2009, p. 43).

Posterior à aprovação da LDB/96, durante o período de 1997 a 2006, houve intensos debates entre grupos defensores das Escolas Normais Superiores e Institutos Superiores de Educação favoráveis à formação dos professores para educação infantil e séries iniciais nos cursos de Pedagogia - não previstas na LDB/96 (UNESCO, 2009).

Desde a aprovação desta lei houve várias iniciativas para formação e titulação de professores em nível superior e em nível médio, buscando atender à referida Lei, além de outras iniciativas que já haviam sido implantadas antes mesmo desta, em diversas instâncias, como por meio de cursos presenciais, semipresenciais e à distância, mas atualmente a demanda para complementação da formação ainda é grande, especialmente para a atuação na educação infantil (UNESCO, 2009).

Em 1999 houve a emissão do Parecer 970/1999, do Conselho Nacional de Educação (CNE) - Câmara de Educação Básica, que retirou do curso de Pedagogia a habilitação de formação para atuação nas séries iniciais, conferindo essa formação ao Curso Normal Superior (PAPI, 2005). A autora afirma ainda que, antes que pudesse ser revisado, o Presidente da República da época, por meio do Decreto $\mathrm{n}^{\circ} 3.276 / 99$ retirou completamente essa possibilidade do curso de Pedagogia, incumbindo exclusivamente o Curso Normal Superior desta função (UNESCO, 2009).

No ano de 2000, devido às mobilizações causadas pela publicação do Decreto, foi emitido um novo Decreto $\mathrm{n}^{\circ} 3.544 / 2000$, alterando a exclusividade (grifo do autor) mencionada no Decreto anterior pela preferência da formação ocorrer em Curso Normal Superior, permitindo que essa função também ocorra nos cursos de Pedagogia (PAPI, 2005).

Um direcionamento maior para o desenvolvimento dos cursos de formação de professores veio em 2006. Neste ano foram aprovadas, pelo CNE, as Diretrizes Curriculares Nacionais (DCN) para Formação de Professores, e nos anos seguintes, as Diretrizes de cada um dos cursos de licenciatura. Mas ainda é possível constatar nos cursos de formação dos professores de licenciatura, a supervalorização do foco disciplinar do conteúdo específico (UNESCO, 2009; GATTI, 2010). Além disso, há a falta de articulação entre as disciplinas das áreas específicas de formação com as disciplinas pedagógicas (UNESCO, 2009).

No mesmo período foram aprovadas também as diretrizes curriculares nacionais para os cursos de Pedagogia, modalidade licenciatura, habilitando estes para atuação na 
educação infantil, séries iniciais, tal como no ensino médio na modalidade normal, para a Educação de Jovens e Adultos (EJA), e formação de gestores escolares, além de áreas outras que demandem conhecimento pedagógico (UNESCO, 2009; GATTI, 2010).

De acordo com Saviani (2008), no conjunto de Metas do Plano Nacional de Educação (PNE) de 1997, há uma meta específica para promover melhorias na Formação de Professores e Valorização do Magistério.

Atualmente, como especificado pelo MEC, podem exercer a docência no Brasil na Educação Básica, nos níveis Fundamental e Médio, profissionais graduados em cursos de Pedagogia e Licenciaturas (BRASIL, s/d). As licenciaturas a que nos referimos são os cursos com formação em áreas específicas e pedagógicas, habilitando o docente a lecionar disciplinas específicas.

$\mathrm{Na}$ Educação Infantil é permitida a docência por profissionais formados ao menos nos cursos da modalidade normal.

Existem em vários municípios os cursos de Formação Docente, em substituição ao Magistério e aos CEFAM. Conforme afirma UNESCO (2009), os CEFAM foram fechados, nos anos posteriores, à promulgação da Lei $n^{\circ}$ 9.394/96, por conta da instituição da formação de tais professores em nível superior.

Para Saviani (2009), embora apresentassem bons resultados, não houve continuidade nos mesmos devido às limitações de seu alcance numérico e à falta de políticas de destinação dos profissionais preparados em tais instituições para as escolas públicas.

Há em vigência no Brasil um Programa Nacional que visa realizar a formação inicial de professores, inclusive em exercício, como o Plano Nacional de Formação de Professores da Educação Básica (PARFOR), que oferece formação em primeira licenciatura para professores que já atuam, mas não tem formação superior; em segunda licenciatura, para docentes em exercício sem a devida formação, atuando a mais de três anos em uma dada disciplina que não a de sua formação; e Formação Pedagógica, para professores que são graduados em cursos que não lhes ofereceu a habilitação em licenciatura, como especificado pela Coordenação de Aperfeiçoamento de Pessoal de Nível Superior (CAPES) (BRASIL, 2010).

Nos últimos anos, tem havidoinvestimento governamental na formação de professores em nível superior. Neste contexto, observamos a existência de Programas de Incentivo, como o Programa Universidade para Todos (ProUni), que oferece desde 
2005 bolsas de estudo em IES particulares para candidatos com renda per capita de até três salários mínimos (BRASIL, s/d).

Outro programa que beneficia candidatos aos cursos de licenciatura é o Fundo de Financiamento ao Estudante do Ensino Superior (Fies), que atende estudantes de baixa renda para auxiliar com as despesas de formação (BRASIL, s/d). Existe ainda o Sistema Universidade Aberta do Brasil (UAB), que oferece formação para professores de Educação Básica preferencialmente à distância, por meio de parcerias com IES públicas, estados e municípios (BRASIL, s/d).

O estímulo a integralização do curso superior de licenciatura é dado também a partir do Programa Institucional de Bolsas de Iniciação à Docência (PIBID) que (sem entrarmos no mérito dos questionamentos das recentes alterações, como a instituição da Residência Pedagógica) tem dado apoio financeiro e de vivência da realidade educacional pela imersão dos professores em formação nas escolas.

Mas ainda falta muito para ser universalizada a formação dos professores ativos em nível superior, isto sem falar nos alunos que ainda devem habilitar no magistério nos cursos profissionalizantes revitalizados.

\section{Considerações finais}

As diversas mudanças no campo educacional, na formação e atuação docente, nos direcionam a dizer que ser professor atualmente é diferente do que era antes. De acordo com Gadotti (2003), em sua essência é apenas diferente, nem melhor nem pior do que fora outrora, porque agora este profissional está incumbido de:

[...] ensinar a pensar; saber comunicar-se; saber pesquisar; ter raciocínio lógico; fazer sínteses e elaborações teóricas, saber organizar o seu próprio trabalho; ter disciplina para o trabalho; ser independente e autônomo; saber articular o conhecimento com a prática; ser aprendiz e autônomo à distância (p. 3).

Ao serem discutidas as questões relativas à educação e principalmente ao fracasso escolar, há muito tempo as questões relativas à formação de professores são um dos focos. E as condições da formação de professores no Brasil, a grosso modo, não são e, ao que tudo indica, nem tão cedo serão satisfatórias, sendo que neste contexto destacam-se as condições dos formados em curso de formação de professores para séries iniciais, que são mais precárias que as demais, uma vez que a atuação pública tem sido somente "complementar e redistributiva, a qual se concentra sobretudo no 
atendimento às regiões com menores indicadores de desenvolvimento econômico e social" (UNESCO, 2009, p. 68).

Assim, embora tenha havido mudanças na formação dos professores no país, ainda há a necessidade de maiores investimentos governamentais e reconhecimento social para que a formação e atuação docente seja mais efetiva para melhorias na formação dos alunos no país.

\section{Referências}

BRASIL. Decreto-Lei $\mathbf{n}^{0}$ 9.394, de 20 de dezembro de 1996. Estabelece a Lei de Diretrizes e Bases da educação nacional. Disponível em: http://www.jusbrasil.com.br/legislacao/109224/leide-diretrizes-e-bases-lei-9394-96. Acesso: 25 jun. 2012.

BRASIL. Plano Nacional de Formação de Professores da Educação Básica - PARFOR. (Coordenação de Aperfeiçoamento de Pessoal em Nível Superior (CAPES). Educação Básica. PARFOR Presencial), 2010. Disponível em: <http://www.capes.gov.br/educacaobasica/parfor>. Acesso: 31 out. 2012

BRASIL. Seja um professor. Website. s/d. Disponível em: <http://sejaumprofessor.mec.gov.br/index.php> Acesso: 25 out. 2012.

CAVALCANTE, M. J. CEFAM: uma alternativa para a formação do professor. São Paulo: Cortez, 1994.

GADOTTI, M. Boniteza de um sonho: ensinar-e-aprender com sentido. Novo Hamburgo: Feevale, 2003.

GATTI, B. A. Formação de professores no Brasil: características e problemas. Educação e sociedade, Campinas, v. 31, n, 113, p. 1355-1379, out./dez. 2010.

HOUAISS, A.; SALLES, M. Dicionário Houaiss da Língua Portuguesa. Rio de Janeiro: Editora Objetiva, 2001.

MALACARNE, V. Formação dos professores e o espaço da Filosofia. São Paulo, 2005. Texto de Qualificação. Faculdade de Educação, Universidade de São Paulo. Mimeo.

MALACARNE, V. Os professores de Química, Física e Biologia da Região Oeste do Paraná: Formação e atuação. São Paulo, 2007. S.f. Tese (Doutorado em Educação) - Faculdade de Educação, Universidade de São Paulo, São Paulo, 2007.

PAPI, S. de O. Professores: formação e profissionalização. Araraquara: Junqueira\&Marin, 2005.

PERES, T. R. Educação brasileira no Império. Disponível em: <http://www.acervodigital.unesp.br/bitstream/123456789/105/3/01d06t03.pdf>. Acesso 16 out. 2012.

SAVIANI, D. Formação de professores: aspectos históricos e teóricos do problema no contexto brasileiro. Revista Brasileira de Educação, Rio de Janeiro, v. 14, n. 40, p. 143-155, jan./abr. 2009. 
TANURI, L. M. História da formação de professores. Revista Brasileira de Educação, Rio de Janeiro, s.v., n. 14, p. 61-88, maio/jun./ago. 2000.

TEIXEIRA, A. Educação não é privilégio. São Paulo: Companhia Editora Nacional, 1968.

UNESCO. United NationsEducational, Scientificand Cultural Organization. Professores do Brasil: impasses e desafios. Coordenado por Bernadete Angelina Gatti e Elba Siqueira de Sá Barreto. - Brasília: UNESCO, 2009.

Recebido em: 06 de dezembro de 2018.

Aceito em: 13 de dezembro de 2018. 